\title{
アーム・多指ハンド機構による把握と操り
}

\author{
永井 清*1 吉川 恒夫*2
}

\section{Grasping and Manipulation by Robotic Arm/Multifingered-Hand Mechanisms}

\author{
Kiyoshi Nagai*1 and Tsuneo Yoshikawa*2
}

\begin{abstract}
A control scheme for grasping and manipulation by arm-hand mechanisms is proposed. The arm-hand mechanisms, discussed in this paper, consist of arm and multifingered hand, and they have the same feature as that of redundant macro-micro manipulator about manipulation. That is; 1) manipulation is possible not only by the arm but also by the hand, 2) the hand is suitable for compliant motion compared to the arm because of the small inertia, and the motion range of the arm is larger than that of the hand. The control scheme can utilize both of the merits of the arm and the hand. Simultaneously, it can realize secure grasping during manipulation. Several simulation results illustrate the validity of the proposed control scheme.
\end{abstract}

Key Words: Grasping and Manipulation, Arm and Multifingered Hand, Redundant Macro-Micro Manipulator, Cooperative Control, Impedance Control

\section{1. はじめに}

マニピュレータ（ロボットアーム）の手先位置制御や力制御 の性能を向上させるために，その先端に小さな付加的装置を装 着して用いることが提案されている $[1] 〜[4]$. このような機構 は一般に, 圥長マクロ・マイクロ・マニピュレータとして見 なすことのできるものであり, 先端部の慣性が小さくなる $[1]$, 位置制御や力制御の带域が広がる [2], などの利点が報告され ている。この問題に対して筆者らは，インピーダンス制御の考 え方に基づき, マクロ部の広い動作範囲とマイクロ部の高い応 答周波数帯域での動作の実現可能性という両者の利点を活かす 制御方法を提案している [5][6].

一方では, マニピュレーション技術の向上のために, 多指口 ボットハンド (以下, 多指ハンド) による把握と操りが研究さ れている. 最近では, 把握と操りに影響を与える, 多指ハン ドや対象物の動力学的特性を考慮した制御則が提案されてい る [7][8]. 筆者らはさらに, 多指ハンドの指先力に対して握力 と操り力を定義し $[9][10]$ ，それらをもとに確実な把握と望み の操りのための制御則を提案している $[11]$.

しかしながら, 多指ハンドの動作範囲は一般に小さいため, 実際の作業のためにはハンドをアームの先端に装着する必要が

原稿受付 1994 年 8 月 9 日

$* 1$ 立命館大学理工学部

$* 2$ 京都大学工学部

${ }^{* 1}$ Ritsumeikan University

${ }^{* 2}$ Kyoto University
ある。このようなアーム・ハンド機構も, ハンドの慣性が小さ い場合には, アームがマクロ部に多指ハンドがマイクロ部に対 応する, 几長マクロ・マイクロ・マニピュレータと見ることが できる.この場合, 操り動作に関しては, マクロ・マイクロ . マニピュレータとしての制御が必要となるが, 同時に把握動作 に関しての制御を, 多指ハンド部に対して行う必要がある。こ のような観点でのアーム・ハンド機構の運動制御の研究は報告 されていない.

そこで本研究では, 多指ハンドとアームの両者の機能と長所 を活かす制御方法を提案する。この制御方法は, 操り動作に関 しては, 多指ハンドがアームと比べて高い動作周波数帯域でそ れを実現できるという長所と, アームが広い動作範囲をもつと いう長所を活かすものである。また, 把握動作に関しては, 文 献 [11] の制御方法と同様に, 多指ハンドが確実な把握動作を実 現するものである.以下， 2 章では基礎式を示し，3 章では制 御方法の提案を行う。また， 4 章ではシミュレーションにより 制御則の有効性を検証する。

\section{2. 基 礎 式}

\section{1 アーム・ハンド機構}

ここでは, 三次元空間の任意の運動にそれぞれが十分な自由 度をもつようなアームと多指ハンドにより構成されるアーム。 ハンド機構を議論の対象とする。このため，アームは 6 関節を 有し, 多指ハンドは, 文献 [9] と同様な仮定のもとに, 3 関節 の指を 3 本もち, 対象物と摩擦のある点接触を行うものとする. この章では, これらを合わせたアーム・多指ハンド機構を対象 
にして, 制御則に必要な基礎式について述べる.

アーム・ハンド機構を Fig. 1 に示す. 議論のために以下の変 数を定義する.

$$
\begin{aligned}
& \Sigma_{\mathrm{B}} \quad \text { : 基準座標系, 原点 } \mathrm{O}_{\mathrm{B}} \\
& \Sigma_{\mathrm{A}} \quad: \text { アーム座標系, 原点 } \mathrm{O}_{\mathrm{A}} \\
& \Sigma_{\mathrm{H}} \quad \text { : ハンド座標系, 原点 } \mathrm{O}_{\mathrm{H}} \\
& \mathrm{C}_{i} \quad: \text { 第 } i \text { 指の指先の接触点（以下, } i=1,2,3 \text { ) } \\
& \boldsymbol{p}_{F i} \in \mathrm{R}^{3} \quad \text { : 点 } \mathrm{O}_{\mathrm{B}} \text { から点 } \mathrm{C}_{i} \text { へ向かう位置ベクトル } \\
& { }^{A} \boldsymbol{p}_{F i} \in \mathrm{R}^{3} \quad \text { : 点 } \mathrm{O}_{\mathrm{A}} \text { から点 } \mathrm{C}_{i} \text { へ向かう位置ベクトル } \\
& { }^{H} \boldsymbol{p}_{F i} \in \mathrm{R}^{3} \quad \text { : 点 } \mathrm{O}_{\mathrm{H}} \text { から点 } \mathrm{C}_{i} \text { へ向かう位置ベクトル } \\
& p \in \mathrm{R}^{3} \quad: \text { 点 } \mathrm{O}_{\mathrm{B}} \text { から点 } \mathrm{O}_{\mathrm{H}} \text { へ向かう位置ベクトル } \\
& p_{A} \in \mathrm{R}^{3} \quad: \text { 点 } \mathrm{O}_{\mathrm{B}} \text { から点 } \mathrm{O}_{\mathrm{A}} \text { へ向かう位置ベクトル } \\
& { }^{A} \boldsymbol{p}_{H} \in \mathrm{R}^{3} \quad \text { : 点 } \mathrm{O}_{\mathrm{A}} \text { から点 } \mathrm{O}_{\mathrm{H}} \text { へ向かう位置ベクトル } \\
& \phi \in \mathrm{R}^{3} \\
& : \Sigma_{\mathrm{B}} \text { から見た } \Sigma_{\mathrm{H}} \text { の姿勢 }
\end{aligned}
$$

（以下，姿勢はロール・ピッチ・ヨウ角）

$$
\begin{aligned}
& \phi_{A} \in \mathrm{R}^{3} \quad: \Sigma_{\mathrm{B}} \text { から見た } \Sigma_{\mathrm{A}} \text { の姿勢 } \\
& { }^{A} \phi_{H} \in \mathrm{R}^{3} \quad: \Sigma_{\mathrm{A}} \text { 方ら見た } \Sigma_{\mathrm{H}} \text { の姿勢 } \\
& \boldsymbol{r}=\left[\boldsymbol{p}^{\mathrm{T}} \boldsymbol{\phi}^{\mathrm{T}}\right]^{\mathrm{T}} \in \mathrm{R}^{6}: \Sigma_{\mathrm{B}} \text { から見た } \Sigma_{\mathrm{H}} \text { の位置姿勢 } \\
& \boldsymbol{r}_{A}=\left[\begin{array}{ll}
\boldsymbol{p}_{A}^{\mathrm{T}} & \phi_{A}^{\mathrm{T}}
\end{array}\right]^{\mathrm{T}} \\
& \in \mathrm{R}^{6} \quad: \Sigma_{\mathrm{B}} \text { から見た } \Sigma_{\mathrm{A}} \text { の位置姿勢 } \\
& { }^{A} \boldsymbol{r}_{H}=\left[\begin{array}{lll}
{ }^{A} \boldsymbol{p}_{H}^{\mathrm{T}} & { }^{A} \boldsymbol{\phi}_{H}^{\mathrm{T}}
\end{array}\right]^{\mathrm{T}} \\
& \in \mathrm{R}^{6} \quad: \Sigma_{\mathrm{A}} \text { から見た } \Sigma_{\mathrm{H}} \text { の位置姿勢 }
\end{aligned}
$$$$
\boldsymbol{\omega} \in \mathrm{R}^{3} \quad: \Sigma_{\mathrm{B}} \text { から見た } \Sigma_{\mathrm{H}} \text { の角速度ベクトル }
$$$$
\boldsymbol{\omega}_{A} \in \mathrm{R}^{3} \quad: \Sigma_{\mathrm{B}} \text { から見た } \Sigma_{\mathrm{A}} \text { の角速度ベクトル }
$$$$
{ }^{A} \boldsymbol{\omega}_{H} \in \mathrm{R}^{3} \quad: \Sigma_{\mathrm{A}} \text { から見た } \Sigma_{\mathrm{H}} \text { の角速度ベクトル }
$$$$
\boldsymbol{v}=\left[\dot{\boldsymbol{p}}^{\mathrm{T}} \boldsymbol{\omega}^{\mathrm{T}}\right]^{\mathrm{T}}
$$$$
\in \mathrm{R}^{6} \quad: \text { 対象物の速度 }
$$$$
\boldsymbol{v}_{A}=\left[\dot{\boldsymbol{p}}_{A}^{\mathrm{T}} \boldsymbol{\omega}_{A}^{\mathrm{T}}\right]^{\mathrm{T}}
$$$$
\in \mathrm{R}^{6} \quad: \text { アーム先端の速度 }
$$$$
{ }^{A} \boldsymbol{v}_{H}=\left[\begin{array}{ll}
{ }^{A} \dot{\boldsymbol{p}}_{H}^{\mathrm{T}} & { }^{A} \boldsymbol{\omega}_{H}^{\mathrm{T}}
\end{array}\right]^{\mathrm{T}}
$$$$
\in \mathrm{R}^{6} \quad: \Sigma_{\mathrm{A}} \text { から見た対象物の速度 }
$$

${ }^{B} \boldsymbol{A}_{H} \in \mathrm{R}^{3 \times 3} \quad: \Sigma_{\mathrm{B}}$ 加ら $\Sigma_{\mathrm{H}} へ$ の姿勢変換行列

${ }^{B} \boldsymbol{A}_{A} \in \mathrm{R}^{3 \times 3} \quad: \Sigma_{\mathrm{B}}$ 少ら $\Sigma_{\mathrm{A}} へ$ の姿勢変換行列

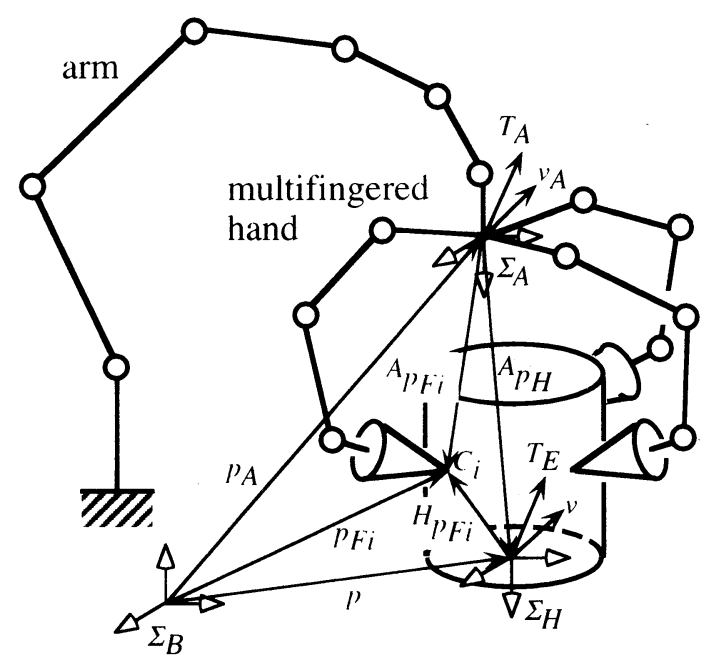

Fig. 1 Arm-hand mechanism

$$
\begin{aligned}
& { }^{A} \boldsymbol{A}_{H} \in \mathrm{R}^{3 \times 3} \\
& : \Sigma_{\mathrm{A}} \text { から } \Sigma_{\mathrm{H}} \text { の姿勢変換行列 } \\
& \boldsymbol{q}_{A} \in \mathrm{R}^{6} \quad: \text { アームの関節変数 } \\
& \boldsymbol{q}_{F i} \in \mathrm{R}^{3} \quad: \text { 第 } i \text { 指の関節変数 } \\
& \boldsymbol{q}_{F}=\left[\begin{array}{lll}
\boldsymbol{q}_{F 1}^{\mathrm{T}} & \boldsymbol{q}_{F 2}^{\mathrm{T}} & \boldsymbol{q}_{F 3}^{\mathrm{T}}
\end{array}\right]^{\mathrm{T}} \\
& \in \mathrm{R}^{9} \\
& \boldsymbol{q}=\left[\boldsymbol{q}_{A}^{\mathrm{T}} \boldsymbol{q}_{F}^{\mathrm{T}}\right]^{\mathrm{T}} \in \mathrm{R}^{15}: \text { 機構全体の関節变数 } \\
& \tau_{A} \in \mathrm{R}^{6} \quad: \text { アームの関節駆動力 } \\
& \boldsymbol{\tau}_{F i} \in \mathrm{R}^{3} \quad: \text { 第 } i \text { 指の関節駆動力 } \\
& \boldsymbol{\tau}_{F} \in \mathrm{R}^{9} \quad: \text { 指の関節駆動力 } \\
& \boldsymbol{\tau}=\left[\boldsymbol{\tau}_{A}^{\mathrm{T}} \boldsymbol{\tau}_{F}^{\mathrm{T}}\right]^{\mathrm{T}} \in \mathrm{R}^{15} \text { : 関節駆動力 } \\
& \boldsymbol{f}_{i} \in \mathrm{R}^{3} \quad: \text { 第 } i \text { 指の指先力 } \\
& \boldsymbol{F}=\left[\begin{array}{lll}
\boldsymbol{f}_{1}^{\mathrm{T}} & \boldsymbol{f}_{2}^{\mathrm{T}} & \boldsymbol{f}_{3}^{\mathrm{T}}
\end{array}\right]^{\mathrm{T}} \\
& \in \mathrm{R}^{9} \\
& T \in \mathrm{R}^{6} \quad \text { : 指が対象物に加える合力 } \\
& \boldsymbol{T}_{A} \in \mathrm{R}^{6} \quad: \text { アーム先端に加わる力 } \\
& \boldsymbol{T}_{E} \in \mathrm{R}^{6} \quad \text { : 対象物に加わる外力 }
\end{aligned}
$$

なお，左肩の添え字は物理量を記述する座標系を表し，基準 座標系で記述する場合は省略する，ただし，姿勢変換行列の場 合のみ $\Sigma_{\mathrm{B}}$ を明示する。

\section{2 把握前の運動学}

この章ではハンドが対象物を把握していない状態の基礎式を 示す.この場合, アーム先端の位置姿勢やその速度, 指先位置 やその速度が明らかにすべき対象になる。

アーム先端の位置, 姿勢, および $\Sigma_{\mathrm{A}}$ から見た第 $i$ 指の指先 位置は次式で表される。

$$
\begin{aligned}
\boldsymbol{p}_{A} & =\boldsymbol{p}_{A}\left(\boldsymbol{q}_{A}\right) \\
{ }^{B} \boldsymbol{A}_{A} & ={ }^{B} \boldsymbol{A}_{A}\left(\boldsymbol{q}_{A}\right) \\
{ }^{A} \boldsymbol{p}_{F i} & ={ }^{A} \boldsymbol{p}_{F i}\left(\boldsymbol{q}_{F i}\right)
\end{aligned}
$$

式 (1)〜 (3) より第 $i$ 指の接触点位置 $\boldsymbol{p}_{F i}$ は, 次式で表される.

$$
\boldsymbol{p}_{F i}=\boldsymbol{p}_{A}+{ }^{B} \boldsymbol{A}_{A}{ }^{A} \boldsymbol{p}_{F i}
$$

速度に関しては, 式（1）（3）をもとに, アーム先端の速度 $\boldsymbol{v}_{A}$ と $\Sigma_{\mathrm{A}}$ から見た指先の速度 ${ }^{A} \dot{\boldsymbol{p}}_{F i}$ を次式のように表すこと ができる.

$$
\begin{aligned}
\boldsymbol{v}_{A} & =\boldsymbol{J}_{A} \dot{\boldsymbol{q}}_{A} \\
{ }^{A} \dot{\boldsymbol{p}}_{F i} & ={ }^{A} \boldsymbol{J}_{F i} \dot{\boldsymbol{q}}_{F i}
\end{aligned}
$$

ただし， $\boldsymbol{J}_{A},{ }^{A} \boldsymbol{J}_{F i}$ はそれぞれ, アームのヤコビ行列と $\Sigma_{\mathrm{A}}$ に 関する第 $i$ 指のヤコビ行列である. $\boldsymbol{v}_{A},{ }^{A} \dot{\boldsymbol{p}}_{F i}$ を用いると, 接 触点の速度 $\dot{\boldsymbol{p}}_{F i}$ は式 (4) より,

$$
\dot{\boldsymbol{p}}_{F i}=\boldsymbol{J}_{A F i} \boldsymbol{v}_{A}+{ }^{B} \boldsymbol{A}_{A}{ }^{A} \dot{\boldsymbol{p}}_{F i}
$$

と表される。ただし，

$$
\begin{aligned}
\boldsymbol{J}_{A F i} & =\left[\begin{array}{lll}
\boldsymbol{E}_{3} & -\boldsymbol{P}_{A F i}
\end{array}\right] \in \mathrm{R}^{3 \times 6}, \quad i=1,2,3 \\
\boldsymbol{P}_{A F i} & =\left[\begin{array}{ccc}
0 & -p_{A F i z} & p_{A F i y} \\
p_{A F i z} & 0 & -p_{A F i x} \\
-p_{A F i y} & p_{A F i x} & 0
\end{array}\right] \\
\boldsymbol{p}_{A F i} & =\left[\begin{array}{lll}
p_{A F i x} & p_{A F i y} & p_{A F i z}
\end{array}\right]^{\mathrm{T}}={ }^{B} \boldsymbol{A}_{A}{ }^{A} \boldsymbol{p}_{F i}
\end{aligned}
$$


である。

結局, 指先速度 $\dot{\boldsymbol{p}}_{F}=\left[\begin{array}{lll}\dot{\boldsymbol{p}}_{F 1}^{\mathrm{T}} & \dot{\boldsymbol{p}}_{F 2}^{\mathrm{T}} & \dot{\boldsymbol{p}}_{F 3}^{\mathrm{T}}\end{array}\right]^{\mathrm{T}} \in \mathrm{R}^{9}$ は, 式 (5) 〜 (7) を $i=1,2,3$ の場合について合わせた後に式 (5) (6) を 代入して得られる次式により表される。

$$
\dot{\boldsymbol{p}}_{F}=\boldsymbol{J} \dot{\boldsymbol{q}}
$$

ただし

$$
\boldsymbol{J}=\left[\begin{array}{cccc}
\boldsymbol{J}_{A F 1} \boldsymbol{J}_{A} & { }^{B} A_{A}{ }^{A} \boldsymbol{J}_{F 1} & 0 & 0 \\
\boldsymbol{J}_{A F 2} \boldsymbol{J}_{A} & 0 & { }^{B} A_{A}{ }^{A} \boldsymbol{J}_{F 2} & 0 \\
\boldsymbol{J}_{A F 3} \boldsymbol{J}_{A} & 0 & 0 & { }^{B} A_{A}{ }^{A} \boldsymbol{J}_{F 3}
\end{array}\right]
$$

である・

\section{3 把握後の運動学}

この章では, アーム先端と対象物の速度の組と, 関節速度の 関係を明らかにする。この際，ハンドが対象物を把握した状態 を議論するため, 把握に伴う指先の運動学的拘束も明らかにす る必要がある。

把握状態において, 対象物の位置 $\boldsymbol{p}$ と姿勢 ${ }^{B} \boldsymbol{A}_{H}$ は, ア一 厶の位置 $\boldsymbol{p}_{A}$ と ${ }^{B} \boldsymbol{A}_{A}$, および多指ハンド部の位置 ${ }^{A} \boldsymbol{p}_{H}$ と姿勢 ${ }^{A} \boldsymbol{A}_{H}$ と，次式で表される関係がある.

$$
\begin{gathered}
\boldsymbol{p}=\boldsymbol{p}_{A}+{ }^{B} \boldsymbol{A}_{A}{ }^{A} \boldsymbol{p}_{H} \\
{ }^{B} \boldsymbol{A}_{H}={ }^{B} \boldsymbol{A}_{A}{ }^{A} \boldsymbol{A}_{H}
\end{gathered}
$$

ここで，多指ハンド部のみに注目し，指先の位置を対象物の 位置姿勢を用いて表すと,

$$
{ }^{A} \boldsymbol{p}_{F i}={ }^{A} \boldsymbol{p}_{H}+{ }^{A} \boldsymbol{A}_{H}{ }^{H} \boldsymbol{p}_{F i}
$$

となる.式 (12) の両辺を時間微分して $i=1,2,3$ をまとめ, $\Sigma_{\mathrm{A}}$ から見た指先速度を ${ }^{A} \dot{\boldsymbol{p}}_{F}=\left[\begin{array}{lll}{ }^{A} \dot{\boldsymbol{p}}_{F 1}^{\mathrm{T}} & { }^{A} \dot{\boldsymbol{p}}_{F 2}^{\mathrm{T}} & { }^{A} \dot{\boldsymbol{p}}_{F 3}^{\mathrm{T}}\end{array}\right]^{\mathrm{T}} \in \mathrm{R}^{9}$, 対象物の速度を ${ }^{A} \boldsymbol{v}_{H} \in \mathrm{R}^{6}$ とすると，

$$
{ }^{A} \dot{\boldsymbol{p}}_{F}={ }^{A} \boldsymbol{J}_{H F}{ }^{A} \boldsymbol{v}_{H}
$$

表すことができる。

一方，式（6）より $i=1,2,3$ を合わせると次式を得る.

$$
{ }^{A} \dot{\boldsymbol{p}}_{F}={ }^{A} \boldsymbol{J}_{F} \dot{\boldsymbol{q}}_{F}
$$

対象物の操り動作中に指先が滑らないときには, 対象物上の 各接触点と, 対応する各指先の速度が等しくなる。すなわち式 (13)（14）より,

$$
{ }^{A} \boldsymbol{J}_{F} \dot{\boldsymbol{q}}_{F}={ }^{A} \boldsymbol{J}_{H F}{ }^{A} \boldsymbol{v}_{H}
$$

が成立し，この式（15）が，把握に伴う指と対象物の運動学的 拘束条件を表す.

把握に伴うこの拘束は, 機構全体の関節速度に着目した拘束 として表すこともできる。この場合，まず， $\Sigma_{\mathrm{B}}$ から見た指先 位置 $\boldsymbol{p}_{F i}$ を次式により表す.

$$
\boldsymbol{p}_{F i}=\boldsymbol{p}_{H}+{ }^{B} \boldsymbol{A}_{H}{ }^{H} \boldsymbol{p}_{F i}
$$

そしてこの式 (16) の両辺を時間微分して $i=1,2,3$ について 合わせ， $\Sigma_{\mathrm{B}}$ から見た指先速度 $\dot{\boldsymbol{p}}_{F}$ を表す次式を得る。

$$
\dot{\boldsymbol{p}}_{F}=\boldsymbol{J}_{H F} \boldsymbol{v}
$$

ただし，

$$
\begin{aligned}
\boldsymbol{J}_{H F}= & {\left[\begin{array}{l}
\boldsymbol{J}_{H F 1} \\
\boldsymbol{J}_{H F 2} \\
\boldsymbol{J}_{H F 3}
\end{array}\right] \in \mathrm{R}^{9 \times 6}, \quad \boldsymbol{J}_{H F i}=\left[\begin{array}{ll}
\boldsymbol{E}_{3} & -\boldsymbol{P}_{H F i}
\end{array}\right] } \\
\boldsymbol{P}_{H F i}= & {\left[\begin{array}{ccc}
0 & -p_{H F i z} & p_{H F i y} \\
p_{H F i z} & 0 & -p_{H F i x} \\
-p_{H F i y} & p_{H F i x} & 0
\end{array}\right] } \\
\boldsymbol{p}_{H F i}= & {\left[\begin{array}{lll}
p_{H F i x} & p_{H F i y} & p_{H F i z}
\end{array}\right]^{\mathrm{T}}={ }^{B} \boldsymbol{A}_{H}{ }^{H} \boldsymbol{p}_{F i} }
\end{aligned}
$$

である。この式（17）と式（8）より次式を得る.

$$
\boldsymbol{J} \dot{\boldsymbol{q}}=\boldsymbol{J}_{H F} \boldsymbol{v}
$$

この式（18）が機構全体の関節速度に着目した場合の運動学的 拘束条件を表す.

さて，以下では機構全体の関節速度の，アーム先端速度と把 握された対象物の速度の組との関係を明らかにする。

まず，関節速度とアーム部とハンド部の関節速度の組の関係 として, 式 (5) (15) より次式を得る。

$$
\left[\begin{array}{c}
\dot{\boldsymbol{q}}_{A} \\
\dot{\boldsymbol{q}}_{F}
\end{array}\right]=\left[\begin{array}{cc}
\boldsymbol{J}_{A}^{-1} & \mathbf{0} \\
\mathbf{0} & { }^{A} \boldsymbol{J}_{F}^{-1}{ }^{A} \boldsymbol{J}_{H F}
\end{array}\right]\left[\begin{array}{c}
\boldsymbol{v}_{A} \\
{ }^{A} \boldsymbol{v}_{H}
\end{array}\right]
$$

一方，対象物の速度 $v \in \mathrm{R}^{6}$ は，次式で表される。

$$
\boldsymbol{v}=\boldsymbol{J}_{A H} \boldsymbol{v}_{A}+{ }^{B} \boldsymbol{R}_{A}{ }^{A} \boldsymbol{v}_{H}
$$

ただし，

$$
\begin{aligned}
\boldsymbol{J}_{A H} & =\left[\begin{array}{cc}
\boldsymbol{E}_{3} & -\boldsymbol{P}_{A H} \\
\mathbf{0} & \boldsymbol{E}_{3}
\end{array}\right] \\
\boldsymbol{P}_{A H} & =\left[\begin{array}{ccc}
0 & -p_{A H z} & p_{A H y} \\
p_{A H z} & 0 & -p_{A H x} \\
-p_{A H y} & p_{A H x} & 0
\end{array}\right] \\
\boldsymbol{p}_{A H} & =\left[\begin{array}{lll}
p_{A H x} & p_{A H y} & p_{A H z}
\end{array}\right]^{\mathrm{T}}={ }^{B} \boldsymbol{A}_{A}{ }^{A} \boldsymbol{p}_{H} \\
{ }^{B} \boldsymbol{R}_{A} & =\left[\begin{array}{cc}
{ }^{B} \boldsymbol{A}_{A} & \mathbf{0} \\
\mathbf{0} & { }^{B} \boldsymbol{A}_{A}
\end{array}\right] \in \mathrm{R}^{6 \times 6}
\end{aligned}
$$

である。式（20）より次式が成立する。

$$
\left[\begin{array}{c}
\boldsymbol{v}_{A} \\
\boldsymbol{v}
\end{array}\right]=\left[\begin{array}{cc}
\boldsymbol{E}_{6} & \mathbf{0} \\
\boldsymbol{J}_{A H} & { }^{B} \boldsymbol{R}_{A}
\end{array}\right]\left[\begin{array}{c}
\boldsymbol{v}_{A} \\
{ }^{A} \boldsymbol{v}_{H}
\end{array}\right]
$$

よって, 式（19）(23）より次式を得る.

$$
\dot{\boldsymbol{q}}=\tilde{\boldsymbol{J}} \tilde{\boldsymbol{v}}
$$

ただし，

$$
\tilde{\boldsymbol{v}}=\left[\begin{array}{c}
\boldsymbol{v}_{A} \\
\boldsymbol{v}
\end{array}\right] \in \mathrm{R}^{12}
$$


は,アーム先端速度と対象物の速度の組であり， $\tilde{J}$ は，

$$
\tilde{\boldsymbol{J}}=\left[\begin{array}{cc}
\boldsymbol{J}_{A}^{-1} & 0 \\
-{ }^{A} \boldsymbol{J}_{F}^{-1 A} \boldsymbol{J}_{H F}{ }^{B} \boldsymbol{R}_{A}^{-1} \boldsymbol{J}_{A H} & { }^{A} \boldsymbol{J}_{F}^{-1 A} \boldsymbol{J}_{H F}{ }^{B} \boldsymbol{R}_{A}^{-1}
\end{array}\right]
$$

である．多指ハンドが対象物を把握している場合には式（18） が成立するが，式（18）において対象物の速度を指定しただけ では $\boldsymbol{J} \dot{\boldsymbol{q}}$ は決まるものの機構全体の関節速度 $\dot{\boldsymbol{q}}$ は一意には決 まらない。 ところが式（24）においては, 対象物の速度 $\boldsymbol{v}$ のほ かに, アーム先端の速度 $\boldsymbol{v}_{A}$ を指定することにより機構全体の 関節速度が決定できることになる，次章で述べる制御則におい ては, 対象物の挙動とアーム先端の挙動を共に指定することに より $\tilde{\boldsymbol{v}}$ が指定されることになる。

$v_{A}, v$ においては，速度の回転成分に対して角速度べクトル を用いているが，制御量として扱うには，その積分值が明確な 意味をもたないために適当でない。そこで，代わりにロール． ピッチ・ヨウ角の時間微分を用いた速度を用いるが，両者の関 係は，次式で表される。

$$
\begin{gathered}
\boldsymbol{v}_{A}=\boldsymbol{W}_{A} \dot{\boldsymbol{r}}_{A} \\
\boldsymbol{v}=\boldsymbol{W} \dot{\boldsymbol{r}}
\end{gathered}
$$

である.式（27）(28）は合わせて

$$
\tilde{\boldsymbol{v}}=\tilde{\boldsymbol{W}} \tilde{\dot{r}}
$$

と表すことができる.ただし，

$$
\begin{gathered}
\tilde{\dot{r}}=\left[\begin{array}{c}
\dot{\boldsymbol{r}}_{A} \\
\dot{\boldsymbol{r}}
\end{array}\right] \\
\tilde{\boldsymbol{W}}=\left[\begin{array}{cc}
\boldsymbol{W}_{A} & \mathbf{0} \\
\mathbf{0} & \boldsymbol{W}
\end{array}\right]
\end{gathered}
$$

である。

\section{4 マニピュレータと対象物の運動方程式}

アーム・多指ハンド機構と対象物の運動方程式はそれぞれ次 式で表される。

$$
\begin{aligned}
& \boldsymbol{M}_{q} \ddot{\boldsymbol{q}}+\boldsymbol{h}_{q}+\boldsymbol{J}^{\mathrm{T}} \boldsymbol{F}=\boldsymbol{\tau} \\
& \boldsymbol{M}_{O} \dot{\boldsymbol{v}}+\boldsymbol{h}_{O}=\boldsymbol{T}+\boldsymbol{T}_{E}
\end{aligned}
$$

ただし，

$$
\boldsymbol{T}=\boldsymbol{J}_{H F}^{\mathrm{T}} \boldsymbol{F}
$$

であり, $M_{q} \in \mathrm{R}^{15 \times 15}$ と $\boldsymbol{h}_{q} \in \mathrm{R}^{15}$ はそれぞれ，機構全体の 慣性行列と非線形項, $M_{O} \in \mathrm{R}^{6 \times 6}$ と $h_{O} \in \mathrm{R}^{6}$ はそれぞれ， 対象物の慣性行列と非線形項である。

\section{5 多指ハンドの把握と操り}

アーム・多指ハンド機構のハンドは, アームとの協調動作に よる操りの最中に，対象物を確実に把握することが必要となる． 筆者らは, 確実な把握と操りを行うために, 多指ハンドの指先 力の成分に対して握力と操り力の定義を行い，指先力を握力と 操り力に分解する方法を示している [9].
ここでは, 3 本指ハンドの握力と操り力について簡単に述 ベる。

握力 $\boldsymbol{F}_{g}=\left[\begin{array}{lll}\boldsymbol{f}_{g 1}^{\mathrm{T}} & \boldsymbol{f}_{g 2}^{\mathrm{T}} & \boldsymbol{f}_{g 3}^{\mathrm{T}}\end{array}\right]^{\mathrm{T}} \in \mathrm{R}^{9}$ は, 対象物に加える合力 が零となる指先力 $\boldsymbol{F}=\left[\begin{array}{lll}\boldsymbol{f}_{1}^{\mathrm{T}} & \boldsymbol{f}_{2}^{\mathrm{T}} & \boldsymbol{f}_{3}^{\mathrm{T}}\end{array}\right]^{\mathrm{T}} \in \mathrm{R}^{9}$ のうち, 各指の静 止摩擦の制限を満足するものとして定義される.ただし， $\boldsymbol{f}_{g i}$ は第 $i$ 指の握力である. 握力は, 各接触点間の内力成分の大き さをその要素にもつ握力パラメー夕を $\boldsymbol{h}_{g} \in \mathrm{R}^{3}$ とすると次式 で表される.

$$
\boldsymbol{F}_{g}=\boldsymbol{B}_{g} \boldsymbol{h}_{g}
$$

一方, 操り力 $\boldsymbol{F}_{m}=\left[\begin{array}{ll}\boldsymbol{f}_{m 1}^{\mathrm{T}} & \boldsymbol{f}_{m 2}^{\mathrm{T}} \boldsymbol{f}_{m 3}^{\mathrm{T}}\end{array}\right]^{\mathrm{T}} \in \mathrm{R}^{9}$ は, 望みの操 り動作に必要な合力を対象物に加える指先力のうち, 各指にお いて握力と逆方向を向かず，握力要素を含まないものとして定 義される.ただし， $\boldsymbol{f}_{m i}$ は第 $i$ 指の操り力である. 操り力は, 力の次元をもつ要素からなる操りカパラメー夕を $\boldsymbol{h}_{m} \in \mathrm{R}^{6}$ と すると次式で表される。

$$
\boldsymbol{F}_{m}=\boldsymbol{B}_{m} \boldsymbol{h}_{m}
$$

上述の定義のもとで指先力 $\boldsymbol{F}$ は, 握力 $\boldsymbol{F}_{g}$ と操り力 $\boldsymbol{F}_{m}$ の 和として次式で表される.

$$
\boldsymbol{F}=\boldsymbol{F}_{g}+\boldsymbol{F}_{m}
$$

\section{3. 制 御 則}

ここでは前章で述べた基礎式をもとに，アーム・多指ハンド 機構の制御則を議論するが，まず，操り動作と把握動作に対す る望みの挙動について述べる.

操り動作に関する望みの挙動として, 以下のインピーダンス 特性がアーム先端と対象物に対して与えられているとする.

$$
\begin{array}{r}
M_{A d} \ddot{\boldsymbol{r}}_{A}+\boldsymbol{D}_{A d} \dot{\boldsymbol{r}}_{A e}+\boldsymbol{K}_{A d} \boldsymbol{r}_{A e}=\boldsymbol{T}_{A} \\
\boldsymbol{M}_{r d} \ddot{\boldsymbol{r}}+\boldsymbol{D}_{r d} \dot{\boldsymbol{r}}_{e}+\boldsymbol{K}_{r d} \boldsymbol{r}_{e}=\boldsymbol{T}_{E}
\end{array}
$$

ただし， $\boldsymbol{M}_{A d} \in \mathrm{R}^{6 \times 6}, \boldsymbol{D}_{A d} \in \mathrm{R}^{6 \times 6}, \boldsymbol{K}_{A d} \in \mathrm{R}^{6 \times 6}$ はそれぞ れ, アーム先端の挙動における望みの慣性行列, 粘性係数行列, 剛性行列であり, $\boldsymbol{M}_{r d} \in \mathrm{R}^{6 \times 6}, \boldsymbol{D}_{r d} \in \mathrm{R}^{6 \times 6}, \boldsymbol{K}_{r d} \in \mathrm{R}^{6 \times 6}$ はそれぞれ, 対象物の挙動における望みの慣性行列, 粘性係数 行列, 剛性行列である.また, $\boldsymbol{r}_{e}\left(=\boldsymbol{r}-\boldsymbol{r}_{d}\right), \boldsymbol{r}_{A e}\left(=\boldsymbol{r}_{A}-\boldsymbol{r}_{A d}\right)$ はそれぞれ, 対象物の位置姿勢の誤差, アーム先端の位置姿勢 の誤差であり, $\boldsymbol{r}_{d}$ は対象物の目標位置姿勢, $\boldsymbol{r}_{A d}$ はアーム先 端の目標位置姿勢である.式（38）(39）の望みの挙動の指定に おいては $\ddot{\boldsymbol{r}}_{A}$ や $\ddot{\boldsymbol{r}}$ の代わりに $\dot{\boldsymbol{v}}_{A}$ や $\boldsymbol{v}$ を用いることも可能で ある. $\boldsymbol{r}_{A d}$ の算出においては, まず, 対象物の目標位置 $\boldsymbol{p}_{d}$ と 目標の姿勢 ${ }^{B} \boldsymbol{A}_{H d}$ のほかに, ハンド部の目標の位置 ${ }^{A} \boldsymbol{p}_{H d}$ と 目標の姿勢 ${ }^{A} \boldsymbol{A}_{H d}$ を用いて, 次式によりアーム先端の目標の 位置 $\boldsymbol{p}_{A d}$ と目標の姿勢 ${ }^{B} \boldsymbol{A}_{A d}$ を得る.

$$
\begin{gathered}
\boldsymbol{p}_{A d}=\boldsymbol{p}_{d}-{ }^{B} \boldsymbol{A}_{A d}{ }^{A} \boldsymbol{p}_{H d} \\
{ }^{B} \boldsymbol{A}_{A d}={ }^{B} \boldsymbol{A}_{H d}{ }^{A} \boldsymbol{A}_{H d}^{-1}
\end{gathered}
$$

そして, 式 (41) の ${ }^{B} \boldsymbol{A}_{A d}$ を用いて, ロール・ピッチ・ヨウ角 で表したアームの目標姿勢 $\phi_{A d}$ を求め, 式 (40) の $\boldsymbol{p}_{A d}$ と合 
わせて $\boldsymbol{r}_{A d}$ とすればよい. また, 式 (38) 中の, アーム先端に 加わる力 $T_{A}$ は通常, 多指ハンド部から伝わる機構内部の力 $T_{A I}$ と同じになる。

通常のインピーダンス制御 [12]においてはアームの先端だけ に望みの機械インピーダンスが指定されるが，ここで提案する 制御則においては，アームの先端と多指ハンドが把握した対象 物の両者に対して, 式 (38) (39) のように望みの機械インピー ダンスが指定される。そして， $T_{A}$ を使うことによって，多指 ハンドの可動範囲の狭さを補償するように, アームを動作させ ることが可能となる.

式（38）（39）は合わせて次式により表現することもできる.

$$
\boldsymbol{M}_{d}\left[\begin{array}{c}
\ddot{\boldsymbol{r}}_{A} \\
\ddot{\boldsymbol{r}}
\end{array}\right]+\boldsymbol{D}_{d}\left[\begin{array}{c}
\dot{\boldsymbol{r}}_{A e} \\
\dot{\boldsymbol{r}}_{e}
\end{array}\right]+\boldsymbol{K}_{d}\left[\begin{array}{c}
\boldsymbol{r}_{A e} \\
\boldsymbol{r}_{e}
\end{array}\right]=\left[\begin{array}{c}
\boldsymbol{T}_{A} \\
\boldsymbol{T}_{E}
\end{array}\right]
$$

ただし，

$$
\begin{aligned}
\boldsymbol{M}_{d} & =\left[\begin{array}{cc}
\boldsymbol{M}_{A d} & \mathbf{0} \\
\mathbf{0} & \boldsymbol{M}_{r d}
\end{array}\right], \quad \boldsymbol{D}_{d}=\left[\begin{array}{cc}
\boldsymbol{D}_{A d} & \mathbf{0} \\
\mathbf{0} & \boldsymbol{D}_{r d}
\end{array}\right] \\
\boldsymbol{K}_{d} & =\left[\begin{array}{cc}
\boldsymbol{K}_{A d} & \mathbf{0} \\
\mathbf{0} & \boldsymbol{K}_{r d}
\end{array}\right]
\end{aligned}
$$

である。

一方, 把握動作に関する望みの挙動に対しては, 握力パラ メータ $\boldsymbol{h}_{g}$ に着目し, 次式を考慮することにする。

$$
\boldsymbol{h}_{g}=\boldsymbol{h}_{g d}
$$

ただし, $\boldsymbol{h}_{g d}$ は握力パラメータの目標值である.この場合, 把 握位置などを考慮して適切に決定する握力パラメータの目標值 への追従により, 確実な把握動作を実現することになる.

さて, 以上の準備のもとで, 前章で述べたアーム・ハンド機 構と対象物に対して，上述の望みの挙動を実現する制御則は， 文献 [13]の動的ハイブリッド制御則や文献 [11] と同様な考え 方に基づき導出され, 以下のように表される.ただし, 添え字 に $d$ をもつ物理量は, 添え字を伴わない物理量と同じ次元をも ち, 制御則の中での目標值に相当するものである.

$$
\begin{aligned}
& \tau_{C}=\tau_{O}+\tau_{A H} \\
& \boldsymbol{\tau}_{O}=\boldsymbol{J}^{\mathrm{T}} \boldsymbol{F}_{d} \\
& \boldsymbol{F}_{d}=\boldsymbol{F}_{g d}+\boldsymbol{F}_{m d} \\
& \boldsymbol{F}_{g d}=\boldsymbol{B}_{g} \boldsymbol{u}_{2} \\
& \boldsymbol{F}_{m d}=\boldsymbol{B}_{m}\left(\boldsymbol{J}_{H F}^{\mathrm{T}} \boldsymbol{B}_{m}\right)^{-1} \boldsymbol{T}_{d} \\
& \boldsymbol{T}_{d}=M_{O} \dot{\boldsymbol{v}}_{d}+\boldsymbol{h}_{O}-\boldsymbol{T}_{E} \\
& \boldsymbol{\tau}_{A H}=\boldsymbol{M}_{q} \ddot{\boldsymbol{q}}_{d}+\boldsymbol{h}_{q} \\
& \ddot{\boldsymbol{q}}_{d}=\tilde{\boldsymbol{J}} \dot{\tilde{\boldsymbol{v}}}_{d}+\dot{\tilde{\boldsymbol{J}}} \tilde{\boldsymbol{v}}_{d} \\
& \dot{\tilde{\boldsymbol{v}}}_{d}=\left[\begin{array}{c}
\dot{\boldsymbol{v}}_{A d} \\
\dot{\boldsymbol{v}}_{d}
\end{array}\right]=\tilde{\boldsymbol{W}} \boldsymbol{u}_{1}+\dot{\tilde{\boldsymbol{W}}} \tilde{\dot{\boldsymbol{r}}} \\
& \boldsymbol{u}_{1}=\left[\begin{array}{c}
\boldsymbol{u}_{1 A} \\
\boldsymbol{u}_{1 r}
\end{array}\right]=\boldsymbol{M}_{d}^{-1}\left\{\left[\begin{array}{c}
\boldsymbol{T}_{A} \\
\boldsymbol{T}_{E}
\end{array}\right]-\boldsymbol{D}_{d}\left[\begin{array}{c}
\dot{\boldsymbol{r}}_{A e} \\
\dot{\boldsymbol{r}}_{e}
\end{array}\right]-\boldsymbol{K}_{d}\left[\begin{array}{c}
\boldsymbol{r}_{A e} \\
\boldsymbol{r}_{e}
\end{array}\right]\right\}
\end{aligned}
$$

$$
\begin{gathered}
\boldsymbol{u}_{2}=\boldsymbol{h}_{g d 2}+\boldsymbol{K}_{F} \int\left(\boldsymbol{h}_{g d 2}-\boldsymbol{h}_{g}\right) d t \\
\boldsymbol{h}_{g d 2}=\boldsymbol{h}_{g d}-T_{c} \dot{\boldsymbol{h}}_{g d 2}
\end{gathered}
$$

ただし, $\boldsymbol{h}_{g d 2}$ は, 握力パラメータの目標值 $\boldsymbol{h}_{g d}$ が時定数 $T_{c}$ の一次遅れ補償器を通過した後の值であり, $\boldsymbol{K}_{F}$ は積分ゲイン である. 式（55）は $\boldsymbol{h}_{g d}$ が不連続に変化することにも対応する ための目標值フィル夕を表す. 式 (44)〜 (55) により算出され る駆動トルク $\boldsymbol{\tau}_{C}$ を式 (32) の $\boldsymbol{\tau}$ として加えればよい. 制御則 中の式 (48) において $\boldsymbol{J}_{H F}^{\mathrm{T}} \boldsymbol{B}_{m}$ が正則であることは付録 1 に 示す. また, 対象物に加わる外力 $\boldsymbol{T}_{E}$ の算出は, 式 (33) を用 いて行う。この際合力 $\boldsymbol{T}$ は, 検出される指先力 $\boldsymbol{F}$ を式 (34) に代入して算出する.

上述の制御則は二つに分けて考えられるものである.一つは 式 (44)〜 (52) で表される系全体の線形化補償器である。この 線形化補償器により,

$$
\begin{gathered}
\ddot{\boldsymbol{r}}_{A}=\boldsymbol{u}_{1 A} \\
\ddot{\boldsymbol{r}}=\boldsymbol{u}_{1 r} \\
\boldsymbol{h}_{g}=\boldsymbol{u}_{2}
\end{gathered}
$$

という, 線形な系が得られる。

もう一つは式 (53)〜 (55) で表される制御器であり, 線形系 に対して望みの挙動を実現させるものである. 式 (53) はイン ピーダンス実現器と呼ぶべきものである.

提案する制御則においては, 系全体の安定性が重要である。 以下ではこの安定性が保証されることについて述べる. 機構全 体の関節変数 $\boldsymbol{q}$ は, 式 (29) (24) の関係があるため, $\boldsymbol{r}_{A}$ と $\boldsymbol{r}$ によりその挙動が決定される.よって $\boldsymbol{r}_{A}$ と $\boldsymbol{r}$ の安定性が補償 されれば, $\boldsymbol{q}$ の安定性についても保証されることになる。この $r_{A}$ と $\boldsymbol{r}$ の安定性は, 望みの挙動を表す式 (42) が安定となる ように $M_{d}, D_{d}$, および $\boldsymbol{K}_{d}$ を指定すれば, 線形化補償の機 能により保証される. 以上のことより機構全体の安定性は保証 される。

\section{4. シミュレーション}

\section{1 並進 1 自由度アーム多指ハンド機構}

ここでは 1 自由度の並進運動を行うアームと多指ハンドで構 成される機構に対して，3 章で提案した制御則を適用した場合 のシミュレーションを行い, 制御則の有効性の検討を行う.

シミュレーションで用いるアームハンド機構を Fig. 2 に示す. 図において $, m_{A}, m_{H}, m_{F 1}, m_{F 2}$ および $m_{O}$ はそれぞれ， アーム, ハンドの台座, 第 1 指, 第 2 指, および対象物の質量 を表す.この場合の機構の運動方程式は, 各部に分けて記述す ると, 以下の式で表される。

$$
\begin{gathered}
\text { アーム }: m_{A} \ddot{q}_{A}=\tau_{A}+T_{A} \\
\text { ハンド台座 }: m_{H} \ddot{q}_{A}=-\tau_{F 1}-\tau_{F 2}-T_{A} \\
\quad \text { 第 } 1 \text { 指 }: m_{F 1}\left(\ddot{q}_{A}+\ddot{q}_{F 1}\right)=\tau_{F 1}-f_{1} \\
\quad \text { 第 } 2 \text { 指 }: m_{F 2}\left(\ddot{q}_{A}+\ddot{q}_{F 2}\right)=\tau_{F 2}-f_{2}
\end{gathered}
$$

式（59）と式（60）を別々にしたのは，アーム先端に加わる力 $T_{A}$ を陽に記述するためである. 式 (59)〜 (62) をまとめて一 


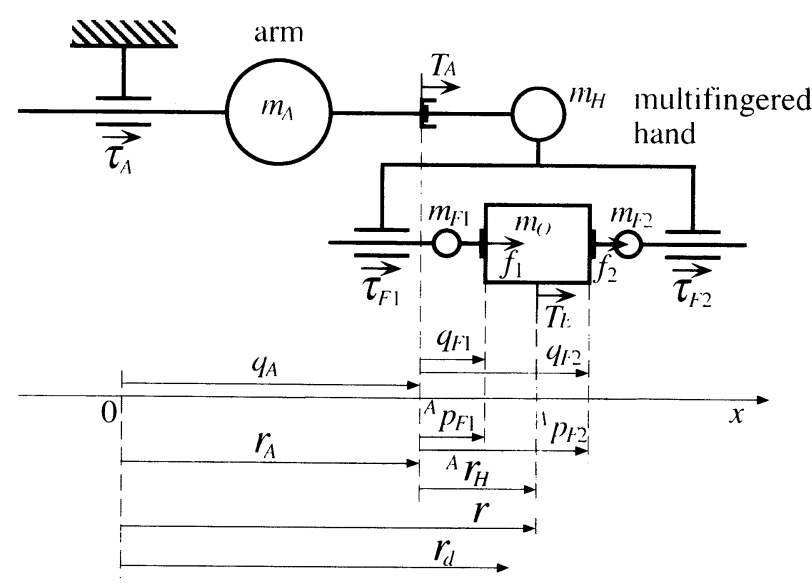

Fig. 21 DOF arm-hand mechanism

つの式にするために，まず，式（59）（60）から $T_{A}$ を消去する と次式を得る.

$$
\left(m_{A}+m_{H}\right) \ddot{q}_{A}=\tau_{A}-\tau_{F 1}-\tau_{F 2}
$$

この式（63）と式（61）(62）を合わせて整理し, 次式を得る.

$$
M_{q} \ddot{\boldsymbol{q}}+\boldsymbol{J}^{\mathrm{T}} \boldsymbol{F}=\boldsymbol{\tau}
$$

ただし $, \ddot{\boldsymbol{q}} \in \mathrm{R}^{3}, \boldsymbol{F} \in \mathrm{R}^{2}, \boldsymbol{\tau} \in \mathrm{R}^{3}$ であり，

$$
\begin{gathered}
\boldsymbol{M}_{q}=\left[\begin{array}{ccc}
m_{A}+m_{H}+m_{F 1}+m_{F 2} & m_{F 1} & m_{F 2} \\
m_{F 1} & m_{F 1} & 0 \\
m_{F 2} & 0 & m_{F 2}
\end{array}\right] \in \mathrm{R}^{3 \times 3} \\
\boldsymbol{J}=\left[\begin{array}{ccc}
1 & 1 & 0 \\
1 & 0 & 1
\end{array}\right] \in \mathrm{R}^{2 \times 3}
\end{gathered}
$$

である。以下, 一般の場合と異なる各変数の次元に注意され たい。

一方, 対象物の運動方程式は次式で表される.

$$
\begin{aligned}
M_{O} \dot{v} & =T+T_{E} \\
T & =\boldsymbol{J}_{H F}^{\mathrm{T}} \boldsymbol{F}
\end{aligned}
$$

ただし $, \dot{v} \in \mathrm{R}^{1}, T \in \mathrm{R}^{1}, T_{E} \in \mathrm{R}^{1}$ であり，

$$
M_{O}=m_{O} \in \mathrm{R}^{1 \times 1}, \quad \boldsymbol{J}_{H F}=\left[\begin{array}{l}
1 \\
1
\end{array}\right] \in \mathrm{R}^{2 \times 1}
$$

である。

また, 運動学に関しては次式が成り立つ。

$$
\begin{gathered}
\dot{\boldsymbol{q}}=\tilde{\boldsymbol{J}} \tilde{\boldsymbol{v}}, \quad \tilde{\boldsymbol{J}}=\left[\begin{array}{cc}
1 & 0 \\
-1 & 1 \\
-1 & 1
\end{array}\right] \in \mathrm{R}^{3 \times 2} \\
v_{A}=W_{A} \dot{r}_{A}, \quad v=W \dot{r}, \quad W_{A}=W=1
\end{gathered}
$$

握力と操り力の和である指先力はこの場合,

$$
\begin{aligned}
\boldsymbol{F} & =\boldsymbol{F}_{g}+\boldsymbol{F}_{m} \\
\boldsymbol{F}_{g} & =\boldsymbol{B}_{g} h_{g}, h_{g} \geq 0, \boldsymbol{B}_{g}=\left[\begin{array}{c}
1 \\
-1
\end{array}\right] \in \mathrm{R}^{2 \times 1}
\end{aligned}
$$

$$
\boldsymbol{F}_{m}=\boldsymbol{B}_{m} h_{m}, h_{m} \geq 0, \boldsymbol{B}_{m}=\left[\begin{array}{c}
k \\
-(1-k)
\end{array}\right] \in \mathrm{R}^{2 \times 1}
$$

となる.ただし, $k(=1$ or 0$)$ の值は, 式 (66) $(69) \sim(71)$ よ り定まる次式,

$$
h_{m}=\left(\boldsymbol{J}_{H F}^{\mathrm{T}} \boldsymbol{B}_{m}\right)^{-1} T
$$

が 0 以上となるように選ばれる $[9]$. この場合式（48）を計算 すると

$$
\boldsymbol{F}_{m d}=\left\{\begin{array}{l}
{\left[\begin{array}{c}
T_{d} \\
0
\end{array}\right], \quad \text { when } \quad T_{d} \geq 0} \\
{\left[\begin{array}{c}
0 \\
T_{d}
\end{array}\right], \quad \text { when } \quad T_{d}<0}
\end{array}\right.
$$

となる

$$
\begin{aligned}
& \text { シミュレーションでは機構の質量を, } \\
& m_{A}=10[\mathrm{~kg}], \quad m_{H}=2.5[\mathrm{~kg}], \quad m_{F 1}=m_{F 2}=0.2[\mathrm{~kg}] \\
& m_{O}=0.1[\mathrm{~kg}]
\end{aligned}
$$

\section{としている.}

\section{2 望みの把握と操り}

3 章の制御則に従う望みの把握動作は, 握力パラメータの目 標值 $h_{g d}$ とサーボ補償器中の定数により決定される.これらの 值を,

$$
h_{g d}=20[\mathrm{~N}], \quad K_{F}=100[1 / \mathrm{s}], \quad T_{c}=0.05[\mathrm{~s}]
$$

とする．

一方, 望みの操り動作は, 把握した対象物とアーム手先に与 える機械インピーダンスにより決定され，

$$
\begin{array}{ll}
M_{A d}=12.5[\mathrm{~kg}] & M_{r d}=0.5[\mathrm{~kg}] \\
D_{A d}=140[\mathrm{~N} /(\mathrm{m} / \mathrm{s})] & D_{r d}=28[\mathrm{~N} /(\mathrm{m} / \mathrm{s})] \\
K_{A d}=800[\mathrm{~N} / \mathrm{m}] & K_{r d}=800[\mathrm{~N} / \mathrm{m}]
\end{array}
$$

とする。これらの設定は, 次の方針に従い決定した。

1）対象物を把握した機構の本来の慣性を考慮する.

2）外力の大きさが一定となる状態において, 多指ハンドの 把握姿勢がもとの状態に戻るようにする.

3）多指ハンドとアームの運動を安定にする.

以下では，これらの方針について詳しく述べる。

1）に関しては, 対象物を把握した機構の運動方程式を明ら かにする必要がある。

まず, 準備として, 式 (67) より次式の加速度の関係を得る.

$$
\ddot{\boldsymbol{q}}=\tilde{\boldsymbol{J}} \tilde{\boldsymbol{v}}
$$

ただし， $\tilde{\boldsymbol{v}}=\left[\begin{array}{ll}\dot{v}_{A} & \dot{v}\end{array}\right]^{\mathrm{T}} \in \mathrm{R}^{2}$ である.また, 式（67）に仮想仕 事の原理を適用し, 次式を得る。

$$
\tilde{\boldsymbol{J}}^{\mathrm{T}} \boldsymbol{\tau}=\tilde{\boldsymbol{T}}
$$


ただし， $\tilde{\boldsymbol{T}}=\left[\begin{array}{ll}T_{A} & T\end{array}\right]^{\mathrm{T}} \in \mathrm{R}^{2}$ である。よって，式 (64) (74) （75）より， $\boldsymbol{\tau}$ と $\ddot{\boldsymbol{q}}$ を消去して次式を得る.

$$
\tilde{\boldsymbol{J}}^{\mathrm{T}} \boldsymbol{M}_{q} \tilde{\boldsymbol{J}} \tilde{\dot{\boldsymbol{v}}}+\tilde{\boldsymbol{J}}^{\mathrm{T}} \boldsymbol{J}^{\mathrm{T}} \boldsymbol{F}=\tilde{\boldsymbol{T}}
$$

ここで式（76）においては， $\tilde{\boldsymbol{J}}$ と $\boldsymbol{J}$ の值を代入すると

$$
\tilde{\boldsymbol{J}}^{\mathrm{T}} \boldsymbol{J}^{\mathrm{T}} \boldsymbol{F}=\left[\begin{array}{c}
0 \\
f_{1}+f_{2}
\end{array}\right]
$$

が成立する。一方, 式 (65) (66) より, 外力 $T_{E}$ が作用しない ときには，

$$
m_{O} \dot{v}=f_{1}+f_{2}
$$

が成立する。また，この場合，式（68）より次式が成り立つ.

$$
\tilde{\dot{\boldsymbol{v}}}=\tilde{\boldsymbol{r}}
$$

よって, 式（76）（79）より対象物を把握した状態の運動方 程式として次式を得る。

$$
M \tilde{\ddot{r}}=\tilde{T}
$$

ただし，

$$
\begin{aligned}
\boldsymbol{M} & =\tilde{\boldsymbol{J}}_{A H}^{\mathrm{T}} \boldsymbol{M}_{q} \tilde{\boldsymbol{J}}_{A H}+\left[\begin{array}{cc}
0 & 0 \\
0 & m_{O}
\end{array}\right] \\
& =\left[\begin{array}{cc}
m_{A}+m_{H} & 0 \\
0 & m_{F 1}+m_{F 2}+m_{O}
\end{array}\right]
\end{aligned}
$$

である。この式（80）が, 系全体の運動方程式を表し， $M$ が 系全体の本来の慣性を表す。式（80）の $\boldsymbol{M}$ と異なる值を望み の慣性として与えた場合には，その差異に対応する駆動力が必 要とされることになる．ここでは, 式（80）の本来の慣性 $M$ と同じ慣性を望みの慣性 $M_{d}$ として与えることとし，

$$
\begin{aligned}
M_{A d} & =m_{A}+m_{H} \\
M_{r d} & =m_{F 1}+m_{F 2}+m_{O}
\end{aligned}
$$

とした。

2）に関しては,アームの先端に与える剛性 $K_{M d}$ を対象物 に与える剛性と合わせて $K_{A d}=K_{r d}$ としている，そしてそれ らの值は, アーム先端の手先の 2 次系の運動としての固有角周 波数 $\omega_{A}$ と $\omega$ が,

$$
\omega_{A}=\sqrt{\frac{K_{A d}}{M_{A d}}}=8[\mathrm{rad} / \mathrm{s}], \quad \omega=\sqrt{\frac{K_{r d}}{M_{r d}}}=40[\mathrm{rad} / \mathrm{s}]
$$

となるように決定している.

一般の場合の剛性の決定に関しては, 文献 [5] と同様に,

$$
\boldsymbol{K}_{A d}=\boldsymbol{J}_{A H d}^{\mathrm{T}} \boldsymbol{K}_{r d} \boldsymbol{J}_{A H d}
$$

とすればよい. 式 (83) 中の $\boldsymbol{J}_{A H d}$ は, 多指ハンド部が望み の姿勢をとるときの点 $\mathrm{O}_{\mathrm{A}}$ から点 $\mathrm{O}_{\mathrm{H}}$ へ向かう位置ベクトル ${ }^{A} \boldsymbol{p}_{H d}$ を用いて式 (21) と同様に計算できる.
3）に関しては,アーム手先と対象物の 2 次系としての運動 の粘性減衰係数 $\zeta_{A}, \zeta$ が共に,

$$
\zeta_{A}=\frac{D_{A d}}{2 \sqrt{M_{A d} K_{A d}}}=0.7, \quad \zeta=\frac{D_{r d}}{2 \sqrt{M_{r d} K_{r d}}}=0.7
$$

となるように $D_{A d}, D_{r d}$ の值を決定している.

手先と多指ハンドの位置と速度の初期值は,

$$
\begin{gathered}
r(0)=0.5[\mathrm{~m}], \quad{ }^{A} r_{H}(0)=0.1[\mathrm{~m}] \\
\dot{q}_{A}(0)=\dot{q}_{F 1}(0)=\dot{q}_{F 2}(0)=0[\mathrm{~m} / \mathrm{s}]
\end{gathered}
$$

とし, 目標位置 $r_{d}$ と ${ }^{A} r_{H d}$ は, 初期値と同じにしている.

\section{3 シミュレーション結果}

この章ではシミュレーション結果について述べるが，その前 に, シミュレーションの手法について説明する。

本研究のシミュレーションにおいては, 把握に伴う指先の拘 束のもとで運動する系を扱う。そのため，ある状態で機構に駆 動トルクが与えられたときに, 指先の拘束を満足する運動とそ のときの指先力を得る必要がある，そこでまず，この点を考慮 した運動方程式を明らかにする。

まず，加速度の関係式として式（18）より次式を得る.

$$
\boldsymbol{J} \ddot{\boldsymbol{q}}+\dot{\boldsymbol{J}} \dot{\boldsymbol{q}}=\boldsymbol{J}_{H F} \dot{\boldsymbol{v}}+\dot{\boldsymbol{J}}_{H F} \boldsymbol{v}
$$

この式（84）と式（33）（34）より $\dot{\boldsymbol{v}} と \boldsymbol{T}$ を消去して次式を 得る.

$\boldsymbol{J} \ddot{\boldsymbol{q}}-\boldsymbol{J}_{H F} \boldsymbol{M}_{O}^{-1} \boldsymbol{J}_{H F}^{\mathrm{T}} \boldsymbol{F}=\boldsymbol{J}_{H F} \boldsymbol{M}_{O}^{-1}\left(\boldsymbol{T}_{E}-\boldsymbol{h}_{O}\right)+\dot{\boldsymbol{J}}_{H F} \boldsymbol{v}-\dot{\boldsymbol{J}} \dot{\boldsymbol{q}}$

よって, 式（85）と式（32）より次式の系全体の運動方程式を 得る。

$$
\tilde{M}_{q}\left[\begin{array}{c}
\ddot{q} \\
F
\end{array}\right]=\tilde{\tau}
$$

ただし

$$
\begin{gathered}
\tilde{\boldsymbol{M}}_{q}=\left[\begin{array}{cc}
\boldsymbol{M}_{q} & \boldsymbol{J}^{\mathrm{T}} \\
\boldsymbol{J} & -\boldsymbol{J}_{H F} \boldsymbol{M}_{O}^{-1} \boldsymbol{J}_{H F}^{\mathrm{T}}
\end{array}\right] \in \mathrm{R}^{5 \times 5} \\
\tilde{\boldsymbol{\tau}}=\left[\begin{array}{c}
\boldsymbol{\tau}-\boldsymbol{h}_{q} \\
\boldsymbol{J}_{H F} \boldsymbol{M}_{O}^{-1}\left(\boldsymbol{T}_{E}-\boldsymbol{h}_{O}\right)+\dot{\boldsymbol{J}}_{H F} \boldsymbol{v}-\dot{\boldsymbol{J}} \dot{\boldsymbol{q}}
\end{array}\right] \in \mathrm{R}^{5}
\end{gathered}
$$

である. 式（86）の $\tilde{M}_{q}$ はフルランクであるので（付録 2 参 照)，与えられた駆動力 $\boldsymbol{\tau}$ に対して $\ddot{\boldsymbol{q}}$ と $\boldsymbol{F}$ を同時に求めるこ とができる。シミュレーション実行時には, サンプリングタイ 厶時間を $1[\mathrm{~ms}]$ として $\ddot{\boldsymbol{q}}$ と $\boldsymbol{F}$ を求め, $\ddot{\boldsymbol{q}}$ からの $\dot{\boldsymbol{q}}$ と $\boldsymbol{q}$ の算 出は，積分時間 $0.1[\mathrm{~ms}]$ のオイラー法を用いている。なお，制 御則中で用いる $T_{A}$ の值は, 式（60）を用いて算出している.

以下に示すシミュレーションの各試行における最初の 1 秒間 は，対象物が初期位置において台に支光られているとし，すべ りのない把握動作を行うための時間にあてている。このため外 力は, 1 秒後に加えることとした

まず, Fig. 3(a) に示す $T_{E}=40[\mathrm{~N}]$ のステップ関数状の外 力を加え, 位置と力の応答を調べた。

操りに関しては, Fig. 3(b) から分かるように, 動作の開始は 同じであるものの対象物の変位の方がアーム先端の変位より 


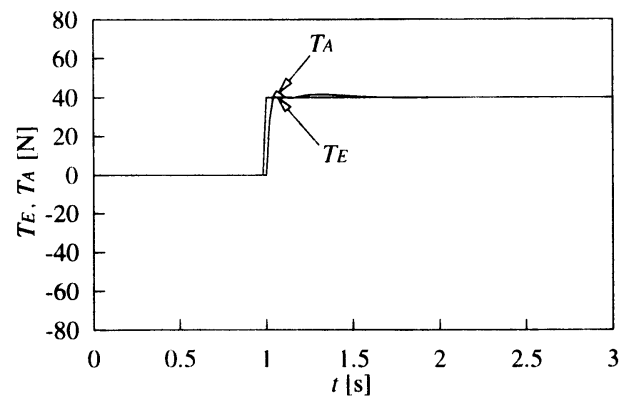

(a) external force

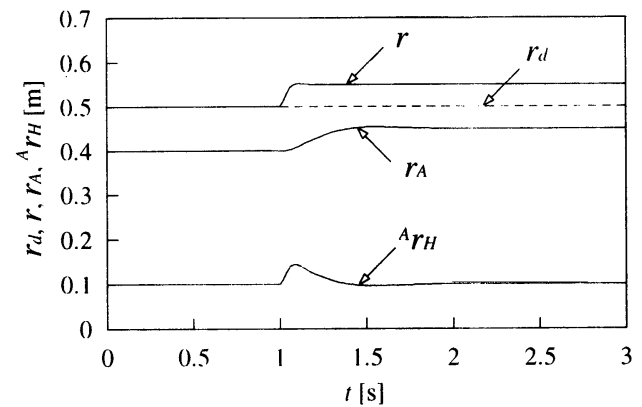

(b) position

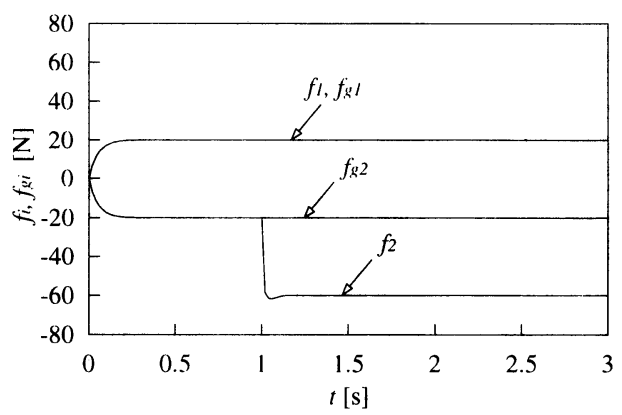

(d) fingertip force and grasping force

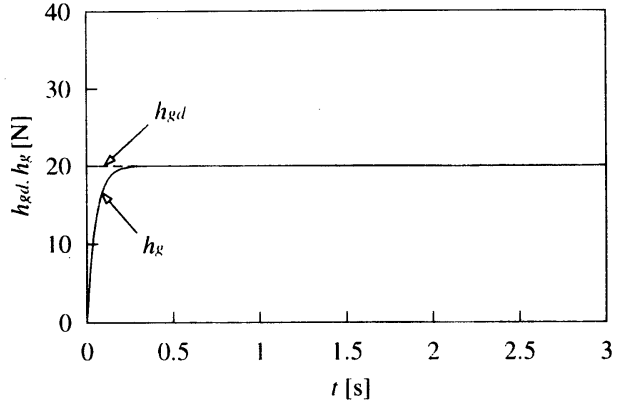

(c) grasping parameter

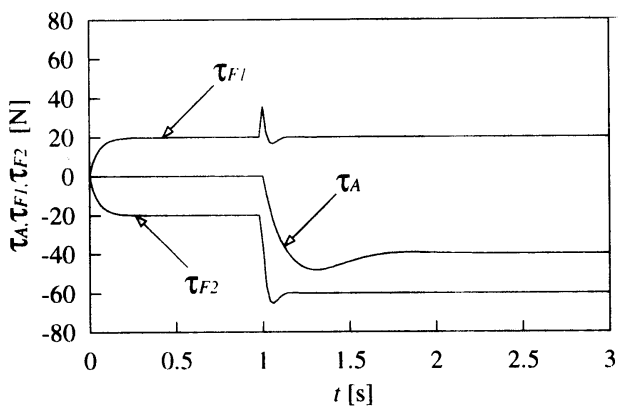

(e) joint force

Fig. 3 Simulation results when external force is changed as step function

素早く現れ, 結果として, 両者の差異であるハンド部の変 位が素早く現れている。これは, 対象物の動作に与えられた $\omega$ の方が, アーム先端の動作に与えられた $\omega_{A}$ より大きいた めである。 そして静止状態に扔いては, 対象物の位置 $r$ が, $T_{E} / K_{r d}=0.05[\mathrm{~m}]$ だけ変位しているが, ハンド部は初期值 ${ }^{A} \boldsymbol{r}_{H}(0)=0.1[\mathrm{~m}]$ に戻り, ハンド部の狭い可動範囲が有効に利 用できる制御則であることが分かる.

把握に関しては, Fig. 3(c) から分かるように, 制御量 $h_{g}$ は シミュレーション開始後まもなく $h_{g d}$ に収束し, 操り動作中 も目標值に追従している，また，Fig. 3(d) に示されているよう に, 各指の握力 $f_{g 1}, f_{g 2}$ の大きさは $h_{g}$ となり, 操り動作開始 後の指先力は, 第 2 指の方だけが内向きに, より大きくなって いる. 仮に第 1 指の方に負の大きさの操り力成分が現れるとす ると, 第 1 指の指先力の大きさが小さくなり, すべりやすい把 握状態となる。

また, Fig. 3(e) に示される駆動力が過大でないのは, 望みの 慣性の設定に扔いて, 対象物を把握した機構の本来の慣性を考
慮したためと考元られる。

次に, 振幅 $40 \mathrm{~N}$ の正弦波状の外力を加え, 位置の応答を調 べた. Fig.4(a) と Fig. 4(b) はそれぞれ周波数が $0.25[\mathrm{~Hz}]$ と $4[\mathrm{~Hz}]$ の場合である. 周波数が $0.25[\mathrm{~Hz}]$ の場合には，主にアー ム部が動作し， $4[\mathrm{~Hz}]$ の場合には，主にハンド部が動作してい る.このことより, 外力の周波数帯域に応じた動作の分担が可 能であることが分かる.

さらに，より一般的な場合を想定し，次式で表される複合正 弦波状の外力を加え, 位置と力の応答を調べた。

$$
T_{E}=a_{1} \sin \left(2 \pi f_{r 1} t^{\prime}\right)+a_{2} \sin \left(2 \pi f_{r 2} t^{\prime}\right)
$$

ただし， $t^{\prime}=t-1(\geq 0)$ であり,ここでは $a_{1}=40[\mathrm{~N}]$, $a_{2}=10[\mathrm{~N}], f_{r 1}=0.25[\mathrm{~Hz}], f_{r 2}=4[\mathrm{~Hz}]$ としている.この 場合の外力を Fig. 5 (a) に示す.

Fig. 5 (b) により, 周波数の低い外力成分に応じてアーム部が 動作し, 周波数の高い外力成分に応じてハンド部が動作してい ることが分かる．このことから考えると，手先に加わる外力が， 


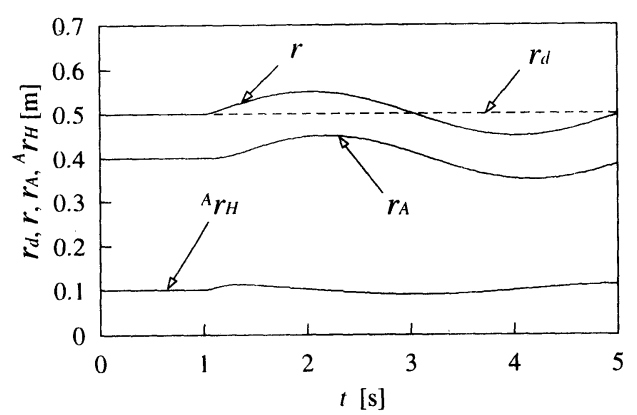

(a) position when $f_{r}=0.25[\mathrm{~Hz}]$

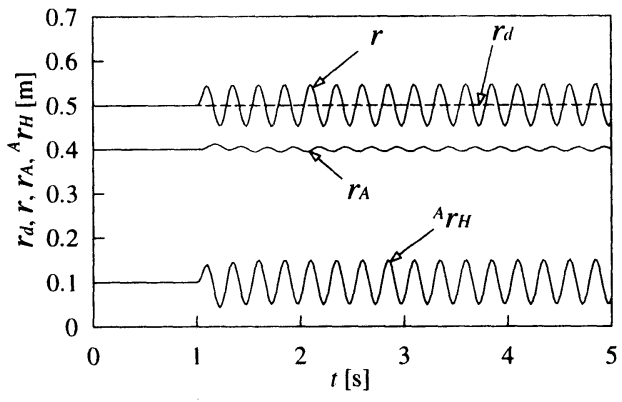

(b) position when $f_{r}=4[\mathrm{~Hz}]$

Fig. 4 Simulation results when external force is changed as sine wave

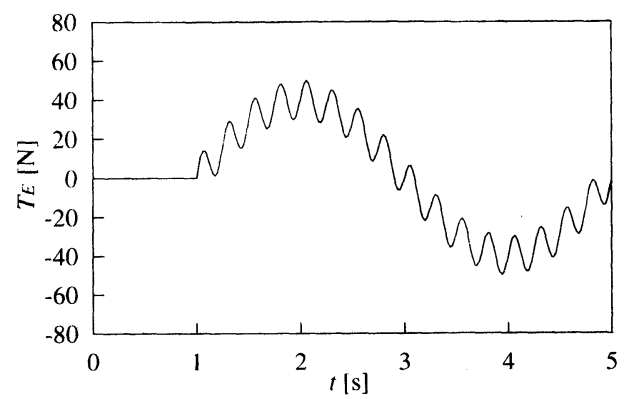

(a) external force

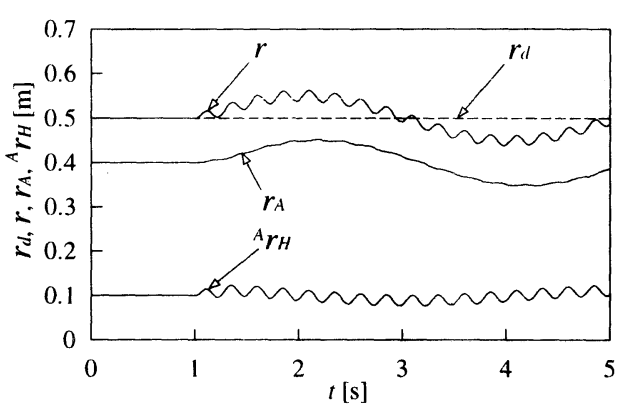

(b) position

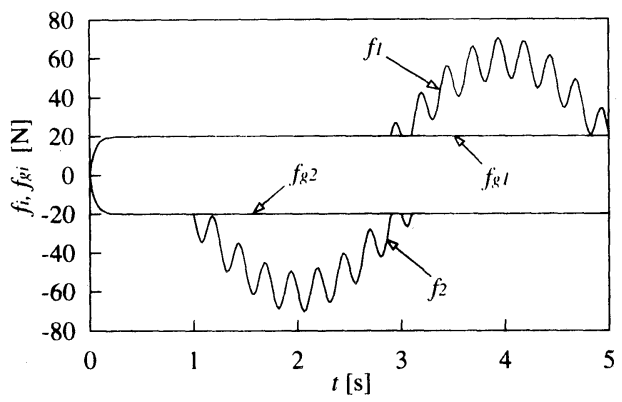

(d) fingertip force and grasping force

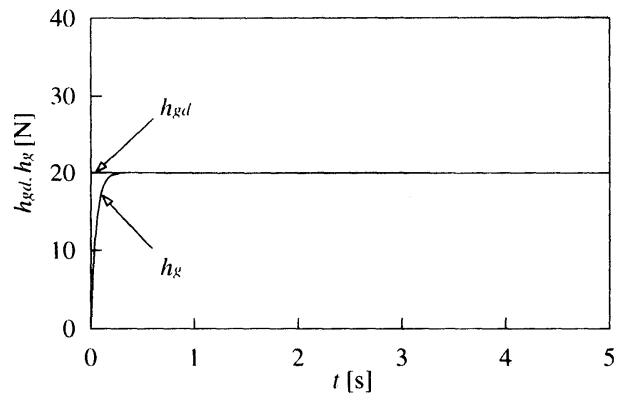

(c) grasping parameter

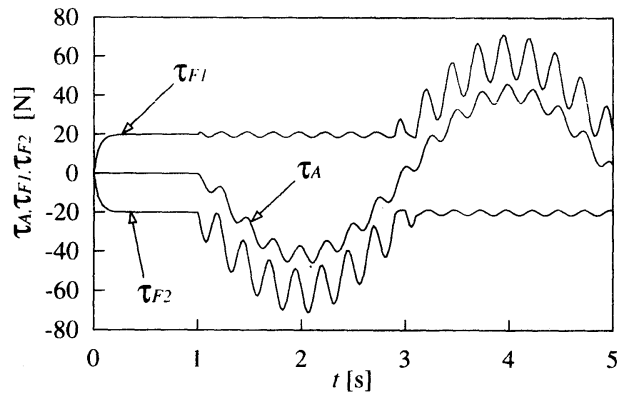

(e) joint force

Fig. 5 Simulation results when external force is changed as composite sine wave

振幅が大きく周波数が低い外力成分と振幅が小さく周波数が高 い外力成分からなる場合には, 前者をアーム部に, 後者をハン ド部に分担させるように望みの機械インピーダンスを設定すれ ばよい，具体的には，本章で述べたように，アーム部先端の固 有角周波数に比べて対象物の固有角周波数が大きくなるように
$M_{A d}$ や $M_{r d}$ などを設定することになる．このような考え方に より, 動作範囲が大きく取りやすいアーム部の長所と柔軟動作 が行いやすいハンド部の長所を活かした制御が可能となる.

この場合の握力パラメータ, 指先力と握力の応答を Fig. 5 (c), Fig. 5 (d) に示す. ステップ関数状の外力を加えた場合と同様に, 
握力パラメータ $h_{g}$ は操り動作中も目標值に収束しており, そ れぞれの指の指先力 $f_{i}$ の大きさは， $h_{g}$ 以上に保たれているこ とが分かる。

また，この際の駆動トルクが過大にならないことが Fig. 5 (e) より分かる.

以上のシミュレーションで用いた制御則においては, 文 献 [9][10] の握力と操り力を用いており, それが確実な把握の ために有効に作用していると思われる. 以下では, このこと を検証するために, 握力と操り力を用いない制御則を構成し, Fig. 5 の場合との比較検討を行う.

握力と操り力を用いない制御則の構成として, 例えば, 式 (46)〜 (48) (54)（55）の代わりに, 次式により指先力の目標值 $\boldsymbol{F}_{d}$ を算出する方法が考元られる.

$$
\begin{gathered}
\boldsymbol{F}_{d}=\tilde{\boldsymbol{F}}_{g d}+\tilde{\boldsymbol{F}}_{m d} \\
\tilde{\boldsymbol{F}}_{g d}=\tilde{\boldsymbol{F}}_{g d 2}+\boldsymbol{K}_{F} \int\left(\tilde{\boldsymbol{F}}_{g d 2}-\tilde{\boldsymbol{F}}_{g}\right) d t \\
\boldsymbol{K}_{F}=\operatorname{diag} \cdot\left(k_{F 1}, k_{F 2}\right) \\
\tilde{\boldsymbol{F}}_{g d 2}=\left[\begin{array}{c}
1 \\
-1
\end{array}\right] h_{g d}-T_{c} \dot{\boldsymbol{F}}_{g d 2} \\
\tilde{\boldsymbol{F}}_{m d}=\left(\boldsymbol{J}_{H F}^{\mathrm{T}}\right)^{\dagger} \boldsymbol{T}_{d}=\left[\begin{array}{l}
T_{d} / 2 \\
T_{d} / 2
\end{array}\right]
\end{gathered}
$$

この方法は, 把握のための指先力成分 $\tilde{\boldsymbol{F}}_{g d}$ を, 指先力と同じ次 元をもつ $\tilde{\boldsymbol{F}}_{g}=\left[\begin{array}{ll}\tilde{F}_{g 1} & \tilde{F}_{g 2}\end{array}\right]^{\mathrm{T}} \in \mathrm{R}^{2}$ を制御量として算出し, 操 りのための指先力成分 $\tilde{\boldsymbol{F}}_{m d}$ を, 疑似逆行列を用いて式 (34) を $\boldsymbol{F}$ について解くことにより算出するものである. 式 (90) に おいては, 把握のための指先力成分の目標値を, Fig. 5 の場合 と同じにするために $h_{g d}$ で与えている。 また，上述の $\tilde{\boldsymbol{F}}_{m d}$ の 算出と整合するような, 指先力 $\boldsymbol{F}$ からの $\tilde{\boldsymbol{F}}_{g}$ の検出方法を付 録 3 に示す.

この算出方法を用い，Fig. 5 の場合と同じ複合正弦波を外力 として与えた場合の位置の応答と $f_{i}, \tilde{f}_{g i}$ の応答を Fig. 6 亿示 す.ただし,この場合, Fig. 5 の場合と同様に

$$
h_{g d}=20[\mathrm{~N}], \quad k_{F i}=100[1 / \mathrm{s}], \quad T_{c}=0.05[\mathrm{~s}]
$$

としている.

Fig. 6 (a) に示す位置の応答は，Fig. 5 (b) と同じであるが，指 先力 $f_{i}$ の応答は異なり, その大きさがつねに $h_{g d}$ 以上になら ないばかりか, 対象物と逆方向を向く瞬間もある。これは, 式 （91）による $\tilde{\boldsymbol{F}}_{m d}$ の算出に起因するものであり, 一定の内力成 分を把握のための目標値として与えるだけでは不十分なことが 分かる.このことより, 本論文で提案する握力と操り力を用い る制御方法のほうが確実な把握を実現しやすいと思われる。

\section{5. おわりに}

本研究で得られた主な結論は以下のと扔りである。

1) アーム・多指ハンド機構に対して，アームと多指ハンド の両者の機能と長所を活かす制御方法を提案している。この制 御方法は, 操り動作に関しては, アームをマクロ部と見なし, 多指ハンドをマイクロ部と見なす，咒長マクロ・マイクロ・マ

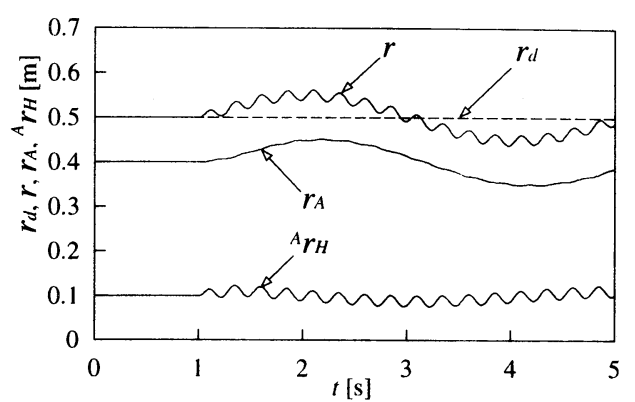

(a) position

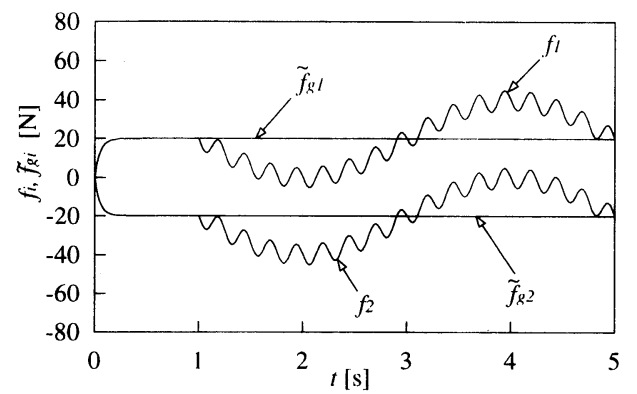

(b) fingertip force and its component for grasping

Fig. 6 Simulation results without the grasping and manipulating forces when external force is changed as composite sine wave

ニピュレータの運動制御の考え方に基づくものである。この制 御方法により, アームの広い動作範囲と多指ハンドの柔軟動作, 実現性の両者を生活かす合理的な協調動作が実現できる。また， 把握動作に関しては, 多指ハンドが確実な把握動作を実現する ための制御方法となる。

2）シミュレーションにより提案する制御系の有効性を検証し ている.

本論文で提案するアーム・ハンド機構の運動制御法は, 口 ボットによる高度なマニピュレーション技術の一つになると思 われる。この制御法は，アームまたは多指ハンドの自由度が少 ない場合にも適用可能 [14] であるが, 詳細な検討は今後の課 題としたい.

\section{参 考 文 献}

[1] O. Khatib: "Reduced effective inertia in macro-/mini-manipulator systems," Proc. of ACC, pp. 2140-2147, 1988.

[2] A. Sharon, N. Hogan and D.E. Hardt: "Controller Design in the Physical Domain," Proc. of the IEEE Conference on Robotics and Automation, pp. 552-559, 1989.

[3] 川瀬, 石川, 澤田, 高田: “手首と腕の協調制御によるマニピュレー タのコンプライアンス制御”, 日本ロボット学会誌, vol. 9, no. 4, pp. 401-408, 1991.

[4]吉川, 細田, 土井：“マクローマイクロシステムによるフレキシブ ルアームの準静的軌道制御”, 日本ロボット学会誌, vol. 11, no. 1, pp. 140-147, 1993.

[5] 永井, 吉川：“インピーダンス制御に基づく圥長マクロマイクロマニ ピュレータの運動制御”, 第 11 回日本ロボット学会学術講演会予稿 集, pp. 267-270, 1993.

[6] 永井, 吉川: “元長マクロ・マイクロマニピュレータのインピーダン ス制御”, 日本ロボット学会誌, vol. 12, no. 5, pp. 766-772, 1994.

[ 7 ] Z. Li, P. Hsu and S. Sastry: "Grasping and Coordinated Manipulation by a Multifingered Robot Hand," Int. Journal of Robotics 
Research, vol. 8, no. 4, pp. 33-50, 1989

[8] T. Yoshikawa and X. Zheng: "Coordinated Dynamic Hybrid Position/Force Control for Multiple Robot Manipulators Handling One Constrained Object," Proc. 1990 JAPAN-U.S.A. Symp. on Flexible Automation, pp. 401-407, 1990.

[9]吉川, 永井: “多指ハンドの操り力と握力”, 計測自動制御学会論文 集, vol. 23, no. 11, pp. 1206-1213, 1987.

[10] T. Yoshikawa and K. Nagai: "Manipulating and Grasping Forces in Manipulation by Multifingered Robot Hands," IEEE Trans. on Robotics and Automation, vol. 7, no. 1, pp. 67-77, 1991.

[11] 永井, 吉川：“多指ハンドの動的操り/揻み制御”, 計測自動制御学会 論文集, vol. 30, no. 1, pp. 39-47, 1994.

[12] N. Hogan: "Impedance Control; An Approach to Manipulation," Parts I-III, ASME Journal of Dynamic Systems, Measurement, and Control, vol. 107, no. 1, pp. 1-24, 1985.

[13] T. Yoshikawa: "Dynamic Hybrid Position/Force Control of Robot Manipulators-Description of Hand Constraints and Calculation of Joint Driving Force," IEEE Trans. on Robotics and Automation, vol. 3, no. 5, pp. 386-392, 1987.

[14] 永井, 吉川：“多指ハンドとアームの協調制御”, 日本ロボット学会第 4 回ロボットシンポジウム予稿集, pp. 155-160, 1994.

\section{付録 $1 \boldsymbol{J}_{H F}^{\mathrm{T}} \boldsymbol{B}_{m}$ が正則であることの証明}

以下では, $\boldsymbol{J}_{H F}^{\mathrm{T}} \boldsymbol{B}_{m}$ に適当な正則行列をかけた行列の正則 性を利用して $\boldsymbol{J}_{H F}^{\mathrm{T}} \boldsymbol{B}_{m}$ が正則であることを証明する。

$\boldsymbol{B}_{m}$ は, 1 または 0 の值をとる補助変数 $k_{1}, k_{2}$ および $k_{3}$ を 含む [10]. ここでは $k_{1}=k_{2}=k_{3}=0$ の場合を考え， $\Sigma_{\mathrm{B}}$ の $x y$ 平面が， $C_{1}, C_{2}, C_{3}$ を通る把握平面に平行となるように とるものとする.

$\Sigma_{B}$ のとり方により

$$
\boldsymbol{B}_{m}=\left[\begin{array}{cccccc}
\mathbf{0} & \overline{\boldsymbol{e}}_{13} & \mathbf{0} & \boldsymbol{e}_{z} & \mathbf{0} & \mathbf{0} \\
\mathbf{0} & \mathbf{0} & \overline{\boldsymbol{e}}_{21} & \mathbf{0} & \boldsymbol{e}_{z} & \mathbf{0} \\
\overline{\boldsymbol{e}}_{32} & \mathbf{0} & \mathbf{0} & \mathbf{0} & \mathbf{0} & \boldsymbol{e}_{z}
\end{array}\right]
$$

となる. ただし， $\boldsymbol{e}_{z}=\left[\begin{array}{lll}0 & 0 & 1\end{array}\right]^{\mathrm{T}}$ である. $\overline{\boldsymbol{e}}_{i j}$ の $z$ 成分 $\left(\overline{\boldsymbol{e}}_{i j}\right)_{z}$ は, $\left(\overline{\boldsymbol{e}}_{32}\right)_{z}=\left(\overline{\boldsymbol{e}}_{13}\right)_{z}=\left(\overline{\boldsymbol{e}}_{21}\right)_{z}=0$ を満たす。他方, $\boldsymbol{J}_{H F}^{\mathrm{T}}$ は, $-\boldsymbol{P}_{H F i}^{\mathrm{T}}=\boldsymbol{P}_{H F i}$ を $\left[\boldsymbol{p}_{i} \times\right]$ と表記する $\left(\boldsymbol{p}_{i}\right.$ は $C_{i}$ までの位置 ベクトル）と，

$$
\boldsymbol{J}_{H F}^{\mathrm{T}}=\left[\begin{array}{ccc}
\boldsymbol{E}_{3} & \boldsymbol{E}_{3} & \boldsymbol{E}_{3} \\
{\left[\boldsymbol{p}_{1} \times\right]} & {\left[\boldsymbol{p}_{2} \times\right]} & {\left[\boldsymbol{p}_{3} \times\right]}
\end{array}\right]
$$

となる.よって，

$$
\boldsymbol{J}_{H F}^{\mathrm{T}} \boldsymbol{B}_{m}=\left[\begin{array}{ccc}
\overline{\boldsymbol{e}}_{32} & \overline{\boldsymbol{e}}_{13} & \overline{\boldsymbol{e}}_{21} \\
\boldsymbol{p}_{3} \times \overline{\boldsymbol{e}}_{32} & \boldsymbol{p}_{1} \times \overline{\boldsymbol{e}}_{13} & \boldsymbol{p}_{2} \times \overline{\boldsymbol{e}}_{21} \\
\boldsymbol{e}_{z} & \boldsymbol{e}_{z} & \boldsymbol{e}_{z} \\
\boldsymbol{p}_{1} \times \boldsymbol{e}_{z} & \boldsymbol{p}_{2} \times \boldsymbol{e}_{z} & \boldsymbol{p}_{3} \times \boldsymbol{e}_{z}
\end{array}\right]
$$

となる.この行列の正則性を以下に示す.

まず，上式と， $\bar{e}_{i j}$ の定義より成り立つ次式，

$$
\left\|\boldsymbol{p}_{1}-\boldsymbol{p}_{2}\right\| \overline{\boldsymbol{e}}_{13}+\left\|\boldsymbol{p}_{2}-\boldsymbol{p}_{3}\right\| \overline{\boldsymbol{e}}_{21}+\left\|\boldsymbol{p}_{3}-\boldsymbol{p}_{1}\right\| \overline{\boldsymbol{e}}_{32}=\mathbf{0}
$$

より, $\boldsymbol{J}_{H F}^{\mathrm{T}} \boldsymbol{B}_{m}$ の前後に正則行列をかけた行列,

$$
\boldsymbol{A}=\left[\begin{array}{cc}
\boldsymbol{E}_{3} & \mathbf{0} \\
{\left[-\boldsymbol{p}_{3} \times\right]} & \boldsymbol{E}_{3}
\end{array}\right] \boldsymbol{J}_{H F}^{\mathrm{T}} \boldsymbol{B}_{m}\left[\begin{array}{ccc|c}
1 & 0 & \left\|\boldsymbol{p}_{3}-\boldsymbol{p}_{1}\right\| & \\
0 & 1 & \left\|\boldsymbol{p}_{1}-\boldsymbol{p}_{2}\right\| & \mathbf{0} \\
0 & 0 & \left\|\boldsymbol{p}_{2}-\boldsymbol{p}_{3}\right\| & \\
\hline \mathbf{0} & \mathbf{0}
\end{array}\right]
$$

$$
\begin{aligned}
& =\left[\begin{array}{ccc}
\overline{\boldsymbol{e}}_{32} & \overline{\boldsymbol{e}}_{13} & \mathbf{0} \\
\hline \mathbf{0} & \left(\boldsymbol{p}_{1}-\boldsymbol{p}_{3}\right) \times \overline{\boldsymbol{e}}_{13} & \boldsymbol{a}
\end{array} \mid\right. \\
& \left.\begin{array}{ccc}
\boldsymbol{e}_{z} & \boldsymbol{e}_{z} & \boldsymbol{e}_{z} \\
\hline-\left\|\boldsymbol{p}_{1}-\boldsymbol{p}_{2}\right\| \overline{\boldsymbol{e}}_{12} & -\left\|\boldsymbol{p}_{2}-\boldsymbol{p}_{3}\right\| \overline{\boldsymbol{e}}_{21} & \mathbf{0}
\end{array}\right]
\end{aligned}
$$

を得る。ただし，

$$
\boldsymbol{a}=\left\{\left\|\boldsymbol{p}_{1}-\boldsymbol{p}_{2}||\left|\boldsymbol{p}_{2}-\boldsymbol{p}_{3}\right| \mid \cos \phi-\right\| \boldsymbol{p}_{2}-\boldsymbol{p}_{3} \|^{2}\right\} \boldsymbol{e}_{z}
$$

であり， $\phi$ はべクトル $\left(\boldsymbol{p}_{2}-\boldsymbol{p}_{1}\right)$ から $\left(\boldsymbol{p}_{3}-\boldsymbol{p}_{1}\right)$ までの $e_{z}$ 軸 まわりの角度である。ここで余弦定理より

$$
\begin{aligned}
\left\|\boldsymbol{p}_{2}-\boldsymbol{p}_{3}\right\|^{2}= & \left\|\boldsymbol{p}_{1}-\boldsymbol{p}_{2}\right\|^{2}+\left\|\boldsymbol{p}_{1}-\boldsymbol{p}_{3}\right\|^{2} \\
& -2\left\|\boldsymbol{p}_{1}-\boldsymbol{p}_{2}|||| \boldsymbol{p}_{1}-\boldsymbol{p}_{3}\right\| \cos \phi
\end{aligned}
$$

であること,ならびに $\boldsymbol{A}$ が

$$
\boldsymbol{A}=\left[\begin{array}{lll|lll}
* & * & 0 & 0 & 0 & 0 \\
* & * & 0 & 0 & 0 & 0 \\
0 & 0 & 0 & 1 & 1 & 1 \\
\hline 0 & 0 & 0 & * & * & 0 \\
0 & 0 & 0 & * & * & 0 \\
0 & * & * & 0 & 0 & 0
\end{array}\right]
$$

の形をしていることに注意すれば,

$$
\begin{aligned}
\operatorname{det} \boldsymbol{A}= & \operatorname{det}\left[\begin{array}{ll}
\overline{\boldsymbol{e}}_{32} & \overline{\boldsymbol{e}}_{13}
\end{array}\right] \\
& \times\left\{\left\|\boldsymbol{p}_{1}-\boldsymbol{p}_{2}\right\|^{2}+\left\|\boldsymbol{p}_{1}-\boldsymbol{p}_{3}\right\|^{2}\right. \\
& \left.\quad-\left\|\boldsymbol{p}_{1}-\boldsymbol{p}_{2}\right\|\left\|\boldsymbol{p}_{1}-\boldsymbol{p}_{3}\right\| \cos \phi\right\} \\
& \times\left\|\boldsymbol{p}_{1}-\boldsymbol{p}_{3}\right\|\left\|\boldsymbol{p}_{2}-\boldsymbol{p}_{3}\right\| \operatorname{det}\left[\begin{array}{ll}
\overline{\boldsymbol{e}}_{12} & \overline{\boldsymbol{e}}_{21}
\end{array}\right] \\
\neq & 0
\end{aligned}
$$

が得られ，A が正則であることが示せる.したがって $\boldsymbol{J}_{H F}^{\mathrm{T}} \boldsymbol{B}_{m}$ は正則である。

またほかの $k_{1}, k_{2}, k_{3}$ の場合についても同様に証明でき る.

付録 $2 \tilde{M}_{g}$ がフルランクであることの証明

正則行列をかけても行列の階数が変化しないことを利用する．

$$
\begin{aligned}
& \operatorname{rank}\left(\tilde{\boldsymbol{M}}_{q}\right) \\
= & \operatorname{rank}\left(\left[\begin{array}{cc}
\boldsymbol{E}_{3} & \mathbf{0} \\
-\boldsymbol{J} \boldsymbol{M}_{q}^{-1} & \boldsymbol{E}_{2}
\end{array}\right] \tilde{\boldsymbol{M}}_{q}\right) \\
= & \operatorname{rank}\left(\left[\begin{array}{cc}
\boldsymbol{M}_{q} & \boldsymbol{J}^{\mathrm{T}} \\
\mathbf{0} & -\boldsymbol{J} \boldsymbol{M}_{q}^{-1} \boldsymbol{J}^{\mathrm{T}}-\boldsymbol{J}_{H F} \boldsymbol{M}_{O}^{-1} \boldsymbol{J}_{H F}^{\mathrm{T}}
\end{array}\right]\right) \\
= & \operatorname{rank}\left(\boldsymbol{M}_{q}\right) \\
& +\operatorname{rank}\left(\left[\begin{array}{ll}
\boldsymbol{J} & \boldsymbol{J}_{H F}
\end{array}\right]\left[\begin{array}{cc}
-\boldsymbol{M}_{q}^{-1} & \mathbf{0} \\
\mathbf{0} & -\boldsymbol{M}_{O}^{-1}
\end{array}\right]\left[\begin{array}{ll}
\boldsymbol{J} & \boldsymbol{J}_{H F}
\end{array}\right]^{\mathrm{T}}\right) \\
= & +2 \\
= & 5
\end{aligned}
$$


付録 3 握力と操りカを用いない場合の $\tilde{F}_{g}$ の算出方法

$$
\begin{aligned}
\tilde{\boldsymbol{F}}_{g} & =\boldsymbol{F}-\tilde{\boldsymbol{F}}_{m} \\
\tilde{\boldsymbol{F}}_{m} & =\left(\boldsymbol{J}_{H F}^{\mathrm{T}}\right)^{\dagger} \boldsymbol{T} \\
\boldsymbol{T} & =\boldsymbol{J}_{H F}^{\mathrm{T}} \boldsymbol{F}
\end{aligned}
$$

$$
\begin{aligned}
\tilde{\boldsymbol{F}}_{g} & =\left\{\boldsymbol{E}_{2}-\left(\boldsymbol{J}_{H F}^{\mathrm{T}}\right)^{\dagger} \boldsymbol{J}_{H F}^{\mathrm{T}}\right\} \boldsymbol{F} \\
& =\left[\begin{array}{cc}
1 / 2 & -1 / 2 \\
-1 / 2 & 1 / 2
\end{array}\right] \boldsymbol{F} \\
& =\left[\begin{array}{c}
\left(f_{1}-f_{2}\right) / 2 \\
\left(-f_{1}+f_{2}\right) / 2
\end{array}\right]
\end{aligned}
$$

\section{より}

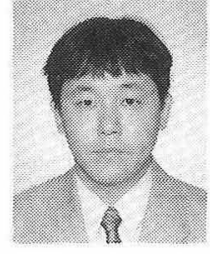

永井 清 (Kiyoshi Nagai)

1959 年 10 月 21 日生. 1983 年京都大学工学部精密 工学科卒業. 1986 年同大学大学院修士課程修了. 1987 年同大学大学院博士課程中途退学. 同年, 立 命館大学理工学部情報工学科助手. 1995 年 4 月よ り同大学助教授. ロボット工学の研究に従事. 工学 博士. システム制御情報学会, 計測自動制御学会, 日本油空圧学会などの会員. (日本ロボット学会正会員)

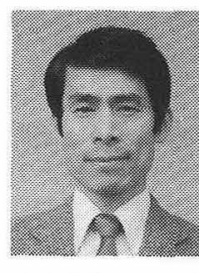

吉川恒夫 (Tsuneo Yoshikawa)

1941 年 12 月 19 日生. 1964 年京都大学工学部精密 工学科卒業. 1969 年同大学大学院博士課程修了. 同 年, 同大学工学部助手. 1970 年同大学助教授. 1986 年同大学教授 (オートメーション研究施設). 1989 年 5 月より同大学工学部応用システム科学教室教 授となり，1991 年 5 月より同大学工学部機械工学 教室教授、ロボット工学および制御工学の研究に従事. 工学博士. シ ステム制御情報学会, 計測自動制御学会, 日本機械学会, IEEEなど の会員.
(日本ロボット学会正会員) 